\title{
An Alternative Premium Payment Method to Finance the Farmers' Pension and Social Security Benefit Scheme
}

\author{
S.P. Withanage, L.H.P. Gunaratne and A.R. Ariyaratne*
}

\begin{abstract}
The farmers' pension and social security benefit scheme (FPSS) which was introduced in 1987 under the Parliament Act No: 12 in 1987, plays a vital role in farmer rehabilitation and welfare. However, as revealed by the official records, the scheme is financially unsustainable and socially less acceptable. Therefore necessary adjustments for the premium payment structure are needed in order to continue this farmer welfare programme. With this background, the aim of this study is to develop an income-based premium payment scheme, as an alternative to the present scheme.

The new premium payment scheme is developed using the Sri Lanka Integrated Survey (SLIS) data following the approaches suggested by Shetty (1971). A field survey was conducted in Kurunegala district to assess the farmers' willingness to pay for the proposed scheme. A probit model was also fitted to find out the factors affecting the decision on willingness to make higher premiums.

The study revealed that $49 \%$ of the respondents are willing to pay for the new income-based scheme. Mean willingness to pay is Rs. 922.00. The analysis further revealed that decision on willingness to pay depends on the age, civil status, occupation and the membership in any other insurance scheme and its' contribution. The study further found the present premium payment scheme can be revised with a different premium and pension payments that can be chosen irrespective of the contributor's age.
\end{abstract}

\footnotetext{
The authors are, respectively, Final Year Undergraduate Student at the time the study was conducted, Senior Lecturer in Agricultural Economics and Business Management, University of Peradeniya and Senior Lecturer in Agricultural Engineering, University of Peradeniya who was the former Chairman of the Agricultural and Agrarian Insurance Board.
} 


\section{Introduction}

Of the various pension and social security benefit schemes, farmers' pension and social security benefit scheme (FPSS) possesses a prominence as it explicitly targets the agricultural workforce in Sri Lanka. The scheme was introduced in 1987 under the provisions of Parliament Act No: 12. The Agricultural and Agrarian Insurance Board (AAIB) is the authorized body assigned with the tasks of implementing and managing the FPSS.

The scheme is voluntary and nominally contributory. The scheme has its own in-built insurance component, which makes provision for the payment of disablement benefits and death gratuities. The scheme is financed by the government and the money paid as premiums to the scheme by the contributors, is called the farmers' pension and social security benefit fund. The contributor is entitled to receive pension on reaching the age of sixty years. The pension payments are varied only with the age of enrolment to the scheme.

The AAIB estimates the farmer community in Sri Lanka to number nearly 2 million, of which approximately 1.0-1.2 millions farmers are estimated to be eligible for the scheme. Of this, more than half or 675,000 of farmers have enrolled in the scheme up to now, whilst the actual number of contributors is approximately 400,000 . The current enrolment is a reasonably satisfactory figure, when considering the fact that the contributions are voluntary, and they pay on their own especially in low income categories.

However, the government has to incur a huge cost to ensure the survival of the scheme. Although, this is considered as a self-help and participatory scheme, government has to bear almost $99 \%$ of the total cost. Agricultural and Agrarian Insurance Board is in a difficult situation to fill the gap of Rs.130 million with declining government support. With this caveat that the government has yet to provide its full financial contribution to the farmers' pension fund that it promised at its inception, the scheme is intended to be self sufficient.

Therefore, the financial sustainability of the scheme is questionable. Since the scheme is not fully matured, current pension payments remain very low. This has gradually increased from Rs.20 million in the early 1990's to just over Rs.116 million in 2001 representing only a small fraction of the 
future payments. The actual administration cost of the scheme is 2-3\% of the overall fund assets (Eriyagama and Rannan-Eliya, 2003). Meanwhile, no revisions have been made to the premium payments, and pensions need to be adjusted for the interest rates and inflation.

The realistic problem is that the premium rates cannot be increased so high since it will become an additional burden for the farmers and as a result farmer participation can be further reduced. Any revision should not affect the poor farmers since about $28 \%$ of the rural farmers live below the poverty line. Therefore, it is vital to re-examine the present scheme in order to restructure the premium payment scheme so as to have a higher premium from those who can afford while maintaining the present level of low premium for low income farmers. A premium payment scheme depending on the farmer's income level and the premium payment capacity will be more effective in financing the farmer pension scheme.

Against this background, the main objective of this study is to develop and to propose an alternative premium payment scheme to finance the farmer's pension and social security benefit scheme. The other objectives include evaluation of the premium payment capacity under different rates in different income categories and analysis of the applicability of the premium payment rates via willingness to pay approach.

The paper is organized as follows: At first the methodology which includes the development of the new scheme and the field testing is presented. This is followed by the results and discussion section which include the present status of the FPSS, proposed scheme, the level of willingness to pay by respondents, and factors affecting their decision on joining the proposed scheme. Finally the conclusions and implications are presented.

\section{Methodology}

Secondary data available in the Sri Lanka Integrated Survey (1999/2000) was used to develop new premium rates. Sri Lanka Integrated Survey (SLIS) of 1999/2000 commissioned by the World Bank was conducted during October 1999 and September 2000, across the whole island including the Northern and Eastern provinces except Kilinochchi and Mullathivu districts. The sample size was 7500 households. However, only the data related to the rural farming sector were used. 
Following Shetty (1971) using the farmer's income levels, expenditure levels and savings/investment levels, premium payment capacity/month of each farmer was calculated as,

$$
\bar{P}=(\bar{Y}-\bar{C})-\bar{I}
$$

where,

$$
\begin{aligned}
& \bar{P}=\text { premium payment capacity/per capita/ month } \\
& \bar{Y}=\text { average income/per capita/month } \\
& \bar{C}=\text { average consumption expenditure/per capita/month } \\
& \bar{I}=\text { average investment allowance/per capita/month }
\end{aligned}
$$

Average premium payment rates were calculated for different income categories analysing the existing pension schemes and concerning its practicability.

Pension payment calculation was done on a compounding basis.

$$
S=\frac{P\left(R^{n}-1\right)}{R-1}
$$

where,

$\mathrm{S}=$ total premium payments

$\mathrm{P}=$ premium payment/year

$\mathrm{R}=$ annual interest rate $(7 \%$ and $8 \%)$

$\mathrm{n}=$ total no of premiums/years

The proposed scheme aimed at correcting the major limitations of the present scheme by inclusion of the ability to adjust the premium based on income. This returns a higher benefit.

At the second stage, the new premium rates were presented to a sample of farmers, to investigate farmer's willingness to pay for an incomebased premium payment structure. Kurunegala district was chosen to conduct the sample survey due to a number of reasons: high enrolment in FPSS and high farming workforce, and availably of different income and tenancy groups 
for the study. Five Agrarian Service Centre (ASC) areas were randomly selected and then from each of the agrarian service centre areas, one Grama Niladhari (GN) division was randomly chosen to select the respondents. A variable number of respondents, proportionate to the number of farm families in the GN division were selected thus making a total sample of 80 respondents (Table 1). The sample included registered as well as non-registered farmers for the FPSS.

Table 1: $\quad$ Sampling plan

\begin{tabular}{|c|c|c|c|c|c|}
\hline \multicolumn{6}{|c|}{ Kurunagala District } \\
\hline ASC & Kurunagala & Pothuhara & Alawwa & $\begin{array}{l}\text { Maharach- } \\
\text { chimulla }\end{array}$ & Mawathagama \\
\hline GN division & Thiththawalla & Walagammulla & Wedeniya & Pangolla & Akade \\
\hline $\begin{array}{l}\text { No. of farm } \\
\text { families }\end{array}$ & 90 & 194 & 135 & 162 & 161 \\
\hline $\begin{array}{l}\text { No. of } \\
\text { respondents }\end{array}$ & 10 & 21 & 15 & 18 & 16 \\
\hline Total & & & 80 & & \\
\hline
\end{tabular}

A pre-tested structured questionnaire with closed-ended questions and statements as appropriate was used for the survey. The questionnaire consisted of five main sections namely, background information, agricultural information, economic characteristics, awareness and knowledge on the FPSS and willingness to pay for the new scheme. In presenting the premium rates, the values were chosen based on their income. The willingness to pay part of the survey was administered carefully following the pattern used in environmental valuation studies (Bateman, 2002). Willingness to pay for an income based premium payment scheme was asked as,

"Are you willing to pay the premium as a rate of monthly/half year income?"

"If the premium is ----------------would you participate in the pension scheme and how much would you at most pay as the premium?"

General socio-economic profile of the respondents and the present status related to the farmers' pension and social security benefit scheme were descriptively analysed. Dichotomous variable (willingness to pay) was used as the dependent variable and probit regression models were fitted to identify 
the factors affecting acceptance of the new scheme. The model was specified as

WTP $(1=$ yes; $0=n o)=f($ demographic and socio-economic variables, farm-specific variables, FPSS related variables)

The demographic socio-economic variables include sex, age occupation, income and civil status whereas farm-specific variables used were land extent and availability of irrigation facilities. The FPSS related variables were membership in agricultural insurance schemes, memberships of other insurance programmes and knowledge on benefits.

\section{Results and Discussion}

\section{Present Status}

The socio-economic information of the respondent farmers is given in Table 2. As depicted in Table 2, majority of the respondents were male, married and full-time farmers. Most of them had education up to GCE (O.L.).

Table 3 presents the details about the enrolment in FPSS. As expected, more married and full-time farmers have enrolled in the FPSS. Although their satisfaction about the social security is high, the respondents have indicated that they are not well aware about the other benefits of the scheme. Only a small fraction (10\%) of the respondents has received benefits during the past three years such as disablement benefits.

Of the reasons for not joining the scheme by the farmers who have not enrolled, low concern/need for the scheme was found to be the most prominent followed by the lack of confidence and trust about the scheme. Informal discussions revealed that even though they have the ability to pay they are not interested about the scheme mainly due to low level of expected returns. These discussions further revealed that FPSS memberships of many have been cancelled due to the discontinuation of the premium payments. Since the field officers are assigned a target of setting the people to join the scheme, in some situations they have enrolled people who do not have the qualifications to join the scheme. Field officers are supposed to visit the members to collect the premiums; otherwise farmers may forget and are not

much interested to pay the premium regularly even though they have the 
ability. As a whole, FPSS members felt that the scheme is satisfactory but they were willing to get a higher pension with lower contribution. In some situations, peoples' attitudes towards the scheme were influenced by political factors.

Table 2: $\quad$ Socio-economics information of the respondent farmers

\begin{tabular}{llc}
\hline Variable & Categories & Percentages \\
\hline \multirow{2}{*}{ Gender } & Male & 70 \\
Age & Female & 30 \\
& Below 30 years & 13.5 \\
& Between 30 - 55 years & 57.5 \\
Civil Status & Above 55 years & 30 \\
& Married & 84 \\
Education & Unmarried & 16 \\
& No schooling & 2 \\
& Primary & 14 \\
Occupation & Secondary (up to O/L) & 67 \\
& Secondary (up to A/L) & 17 \\
Farming Experience & Full time farming & 68 \\
& Part time farming & 32 \\
& $1-10$ years & 20 \\
Land Extent & $10-20$ years & 50 \\
& 20< years & 30 \\
& Less than 1ha & 48 \\
& $1-2$ ha & 37 \\
& $>2$ ha & 12 \\
\hline
\end{tabular}


Table 3: $\quad$ Details about the members of the FPSS

\begin{tabular}{llc}
\hline Variables & Categories & Percentages \\
\hline \multirow{2}{*}{ Age at joining } & Below 30 years & 17 \\
& 30 - 55 years & 68 \\
& Above 55 years & 15 \\
Level of the awareness & High & 16 \\
of the benefits & Moderate & 18 \\
& Low & 66 \\
Satisfaction & High & 65 \\
& Moderate & 31 \\
Benefits received & Low & 4 \\
& Yes & 10 \\
& No & 90 \\
\hline
\end{tabular}

There were some administrative problems such as lack of coordination between the grass root level supporting officers and the Agricultural Insurance Board. In addition, insufficient number of field officers and their poor awareness about the new policies and decisions on the scheme also appear to be constraints. Field officers said that the discount basis premium payment method should be arranged again so as to have two or four payments per year.

\section{Proposed Scheme}

As indicated above, in order to attract more and to increase the satisfaction of the existing members, joining age and the premium have been adjusted in the proposed scheme which guarantees an attractive pension/disability payment. Tables 4 and 5 provide the scheme as developed using the methodology described in the previous section. Then depending upon the age and income of the respondent, appropriate payments are presented. 
Table 4: $\quad$ Proposed premium and pension payment scheme - 7\% interest rate

\begin{tabular}{|c|c|c|c|c|c|c|}
\hline \multirow{2}{*}{$\begin{array}{l}\text { Six } \\
\text { months } \\
\text { Income }\end{array}$} & \multirow{2}{*}{$\begin{array}{l}\text { Premium } \\
\text { payment } \\
\text { (six month) } \\
\text { Rate-7\% } \\
\end{array}$} & \multirow{2}{*}{$\begin{array}{l}\text { With } \\
\text { Government } \\
\text { involvement } \\
\text { of } 5 \% \\
\text { (Total)-12\% }\end{array}$} & \multicolumn{4}{|c|}{ Pension payment } \\
\hline & & & $\begin{array}{l}\text { Joining } \\
\text { age } 18\end{array}$ & $\begin{array}{l}\text { Joining } \\
\text { age } 25\end{array}$ & $\begin{array}{l}\text { Joining } \\
\text { age } 35\end{array}$ & $\begin{array}{l}\text { Joining } \\
\text { age } 40\end{array}$ \\
\hline 12000 & 840 & 1440 & 2768 & 1659 & & \\
\hline 18000 & 1260 & 2160 & 4151 & 2488 & 1138 & \\
\hline 24000 & 1680 & 2880 & 5535 & 3318 & 1518 & \\
\hline 30000 & 2100 & 3600 & 6919 & 4147 & 1897 & 1230 \\
\hline 36000 & 2520 & 4320 & 8303 & 4977 & 2277 & 1476 \\
\hline 42000 & 2940 & 5040 & 9687 & 5806 & 2656 & 1722 \\
\hline 48000 & 3360 & 5760 & 11070 & 6635 & 3036 & 1968 \\
\hline 54000 & 3780 & 6480 & 12454 & 7465 & 3415 & 2214 \\
\hline 60000 & 4200 & 7200 & 13838 & 8294 & 3795 & 2460 \\
\hline
\end{tabular}

\section{Willingness to Pay for the Proposed Scheme}

When the farmers were presented with the new scheme their responses were varied. Only forty nine percent of the respondents have expressed their willing to participate in the income-based premium payment scheme and to pay the proposed premiums while the other $51 \%$ of the respondents were reluctant to accept the new scheme. Of these people, the majority $(49 \%)$ of the respondents who were not willing to pay for the new scheme stated that the rates/amounts are high while others indicated that the premium is fine (39\%) and income is not fixed (12\%). The mean willingness to pay for the proposed scheme is found to be Rs. 922.00. 
60

Table 5: $\quad$ Proposed premium and pension payment scheme - 8\% interest rate (continued)

\begin{tabular}{|c|c|c|c|c|c|c|}
\hline \multirow{2}{*}{$\begin{array}{c}\text { Six } \\
\text { months } \\
\text { income }\end{array}$} & \multirow{2}{*}{$\begin{array}{c}\text { Premium } \\
\text { payment } \\
\text { (six month) } \\
\text { Rate-7\% }\end{array}$} & \multirow{2}{*}{$\begin{array}{c}\text { With } \\
\text { Government } \\
\begin{array}{c}\text { Involvement } \\
\text { of } 5 \%\end{array} \\
\text { (Total)-12\% }\end{array}$} & \multicolumn{4}{|c|}{ Pension payment } \\
\hline & & & $\begin{array}{l}\text { Joining } \\
\text { age } 18 \\
\end{array}$ & $\begin{array}{l}\text { Joining } \\
\text { age } 25\end{array}$ & $\begin{array}{l}\text { Joining } \\
\text { age } 35\end{array}$ & $\begin{array}{l}\text { Joining } \\
\text { age } 40\end{array}$ \\
\hline 12000 & 840 & 1440 & 4172 & 2363 & & \\
\hline 18000 & 1260 & 2160 & 6259 & 3545 & 1504 & \\
\hline 24000 & 1680 & 2880 & 8345 & 4726 & 2005 & \\
\hline 30000 & 2100 & 3600 & 10431 & 5908 & 2506 & 1569 \\
\hline 36000 & 2520 & 4320 & 12517 & 7090 & 3008 & 1883 \\
\hline 42000 & 2940 & 5040 & 14604 & 8271 & 3509 & 2197 \\
\hline 48000 & 3360 & 5760 & 16690 & 9453 & 4010 & 2510 \\
\hline 54000 & 3780 & 6480 & 18776 & 10634 & 4512 & 2824 \\
\hline 60000 & 4200 & 7200 & 20862 & 11816 & 5013 & 3138 \\
\hline
\end{tabular}

\section{Factors Affecting Willingness to Pay (WTP)}

As described in the methodology section, the factors affecting willingness to join the new scheme were identified by probit modelling with a set of explanatory variables that represent demographic and socio-economic, farm-specific and insurance related situation of a respondent. Table 5 gives the results of the maximum livelihood estimations of the probit model. 
Table 5: $\quad$ Estimates of the probit model

\begin{tabular}{lccc}
\hline Variable & $\begin{array}{c}\text { Estimated } \\
\text { Coefficient }\end{array}$ & $\begin{array}{l}\text { Standard } \\
\text { Error }\end{array}$ & t-ratio \\
\hline Sex (1= male) & 0.1475 & 0.4321 & 0.3414 \\
Age (years) & 0.0823 & 0.0274 & $3.0042^{* *}$ \\
Civil status (1= married) & -2.1159 & 0.7648 & $-2.7664^{* *}$ \\
Education (years in the school) & 0.0584 & 0.0681 & 0.8583 \\
Occupation (1= full time farming) & 0.9315 & 0.5081 & $1.8331^{*}$ \\
Land extent (hectares) & -0.2643 & 0.2369 & -1.1158 \\
Irrigation (1= irrigated) & -0.9942 & 1.0139 & -0.9806 \\
Annual income (Rs.) & 0.0055 & 0.0069 & 0.7956 \\
Member of other insurance (1=yes) & 0.0036 & 0.0017 & $2.0696^{* *}$ \\
Knowledge on benefits (1=yes) & -0.0432 & 0.5028 & -0.8602 \\
Present membership (1=yes) & -0.4365 & 0.5051 & -0.8642 \\
Constant & -2.3093 & 1.5638 & -1.4767 \\
Log (L) & -179.04 & & \\
Pseudo R & & & \\
\hline$*$ significa & 0.234 & & \\
\hline
\end{tabular}

* significant at $\alpha=0.1$; ** significant at $\alpha=0.05$.

Of the variables considered, some of the variables had no impact on their willingness to enroll in the proposed income based insurance scheme. Level of education, gender of the respondents, land area, whether irrigation facilities are available or not, annual income and membership of the present FPSS do not influence their decision. The analysis revealed that when farmers become older, they feel the need for a higher pension payment to join incomebased scheme. Contrary to expectation, married farmers were reluctant to the join the proposed scheme possibly due to high household expenditure. The new schemes appeared to be more attractive to the full-time farmers compared to that of part-time farmers. People with other insurance schemes expressed their willingness to join this too, may be due to their high income. However, 
this income-based scheme was not attractive to influential farmers (i.e. high income, irrigated and higher farm-size). This is crucial as the target customers of the alternative scheme are these farmers. This implies the need for a sound awareness scheme. The variables that influence willingness to pay are discussed below.

\section{Decision on Willingness to Pay with Age}

When the age increases, people tend more to indicate their willingness to pay for the new scheme (Figure 1). This is because of the structure of the farming community i.e., younger population is moving away from farming. The older people are more concerned with their own social security. Therefore the scheme is more attractive to the older generation.

\section{Decision on Willingness to Pay with Civil Status}

As shown in the Figure 2, contrary to the expectations, more unmarried people prefer the new scheme. This might be due to the unmarried farmers having relatively more savings for their own security.

Figure 1: Willingness to pay with age

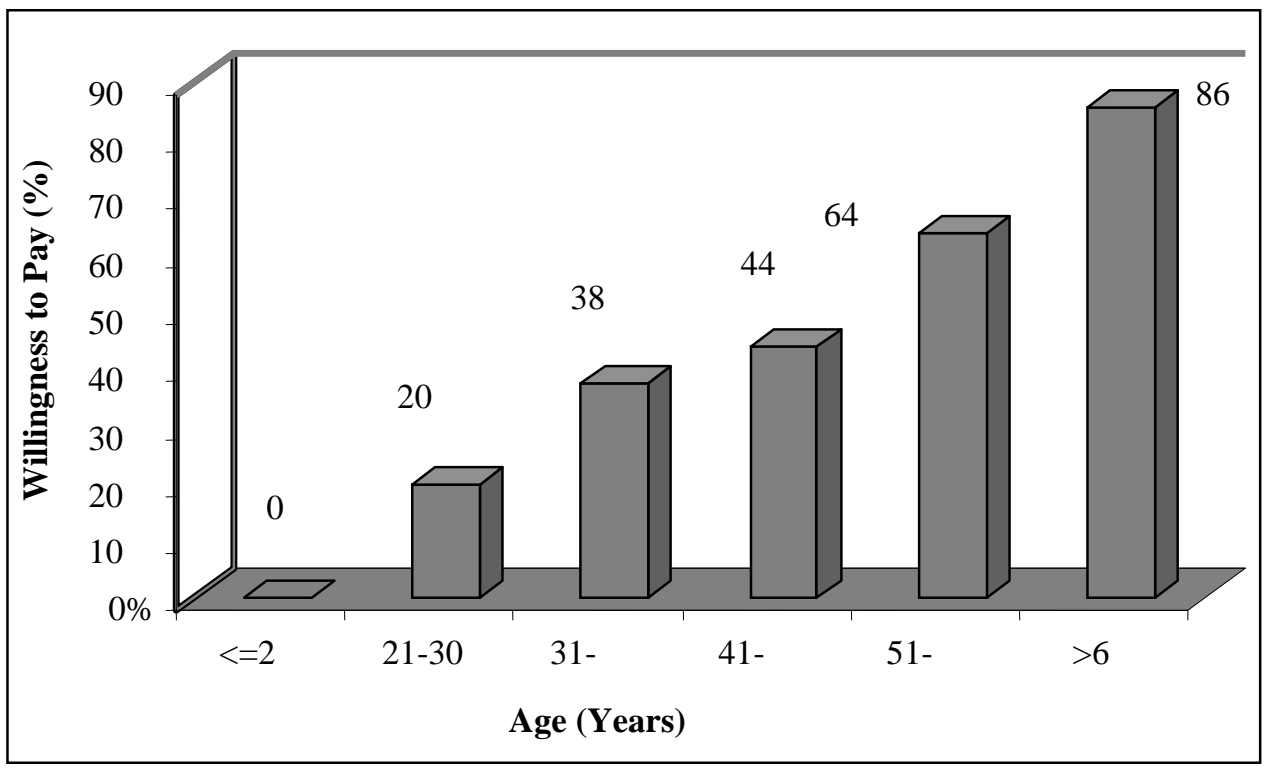


Figure 2. Willingness to pay with civil status

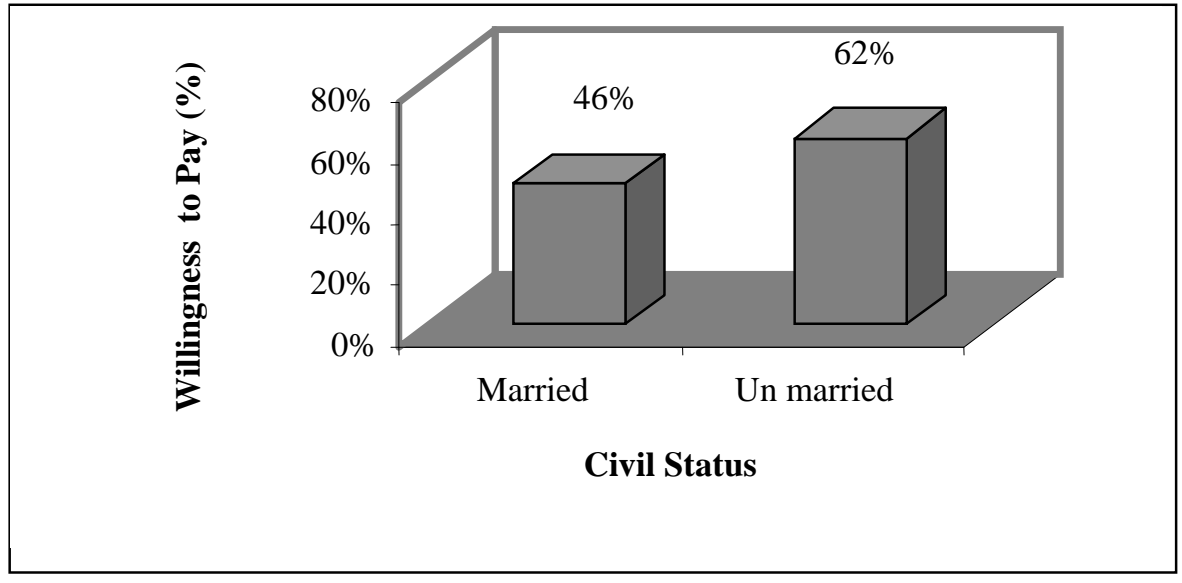

Decision on Willingness to Pay with Occupation (Farming Status)

Occupation of the respondent is a very important factor for the decision on willingness to pay. People who engage in farming as a full-time occupation are more willing to pay for the new scheme (Figure 3). Another important factor is that the income level of the respondent is not a major factor for the decision. Even though the people who engage in farming as well as other occupational categories have higher income levels, they are not willing to pay for the scheme. 
Figure 3: Willingness to pay with occupation

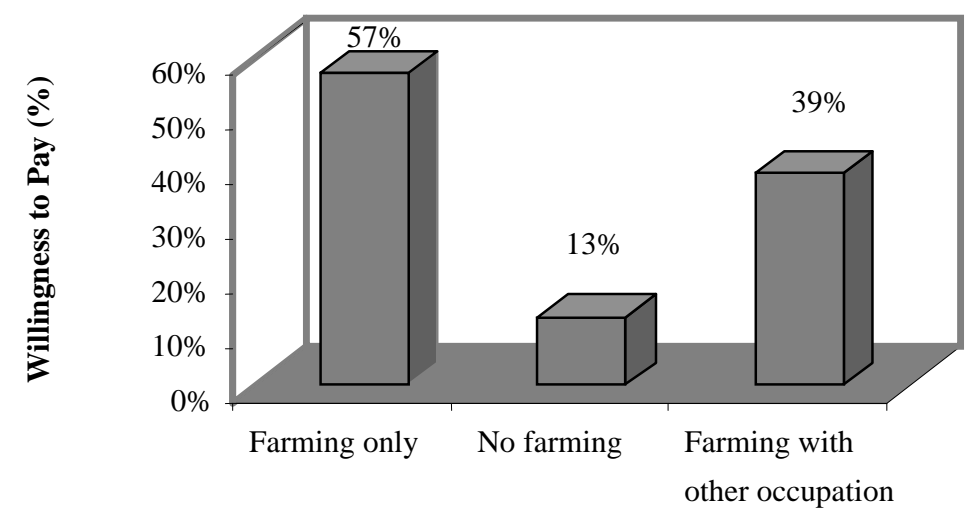

Occupation

Figure 4: Memberships in other schemes

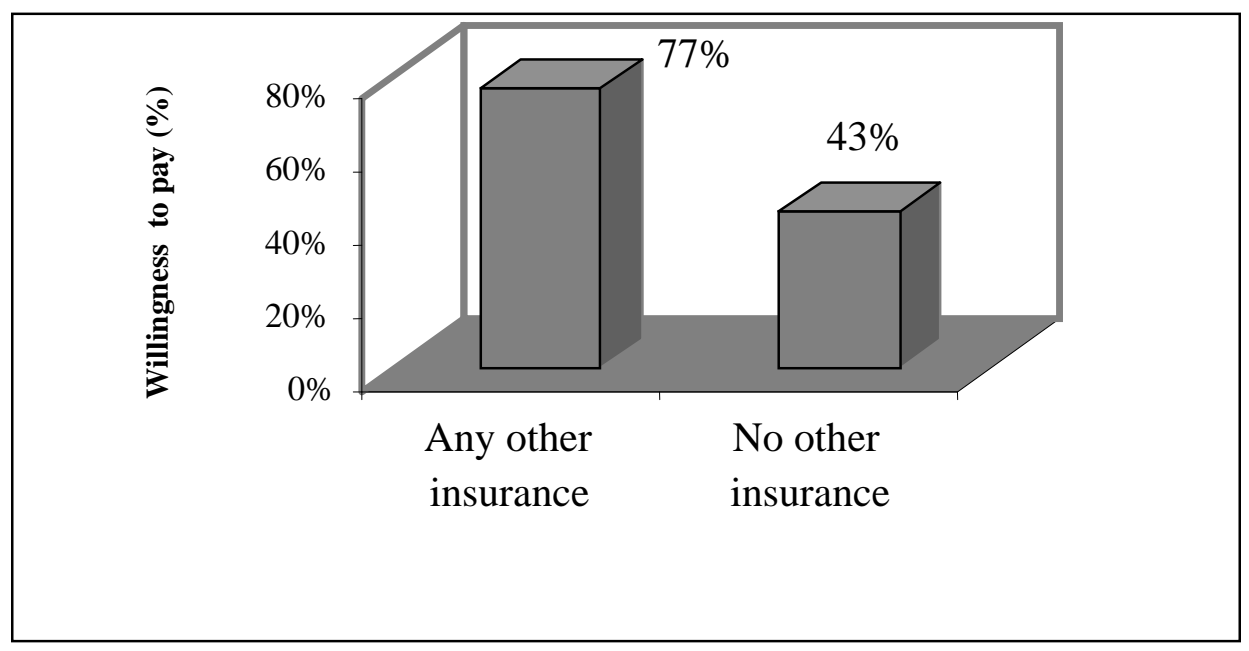




\section{Decision on Willingness to Pay with Membership in Any Other Insurance Scheme}

People who have joined other insurance schemes and paying higher amounts are also willing to pay for this new scheme. This is because of the awareness and the concern on the social security benefits. But the proportion of people having any other insurance scheme is very low. The farming population is not very aware about the social security and benefit schemes as well as saving habits.

\section{Conclusions and Policy Implications}

As discussed earlier, the major drawback of the present FPSS is the fixed premium rates and the age structure. This is not attractive to the farmers who would like to pay more and expect to get better benefits. This issue needs to be addressed in order to implement this as a self-sustained programme while continuing the welfare benefits to the farmers. Forty nine percent of the respondents in the sample are willing to participate in the new scheme and would like to pay the proposed premium amounts. However, they are willing to pay only the lower amounts of the proposed scheme i.e., Rs. 840.00, $1,260.00,1,680.00,2,100.00$ are the amounts achievable. Mean willingness to pay for the new scheme is Rs. 922.00. Decision on willingness to pay depends on the age, civil status, occupation of the respondent and membership in any other insurance scheme as well as its premium contribution. Older population and unmarried people are more willing to pay for the scheme than the younger and married people. Also full time farmers and people having other insurance policies and paying higher premiums are more willing to participate in the new scheme.

It is worthwhile to note that even though forty nine percent of the respondents are willing to participate in an income based premium payment scheme, still they are reluctant to pay a higher amount which is needed to convert the scheme into a financially viable one. Although the higher rates are not achievable, lower amounts of the scheme are quite reasonable. This implies the premium payments can be increased and revised within a limit, 
based on the income. Scheme can be revised so as to have several premium payments and pension payments that can be chosen by the contributors of the scheme, without restricting to the age of the contributor.

Adjustments to the pension payments as well as the premium payments according to the inflation, life expectancy and the interest rates are very essential for the long-term sustainability of the scheme. Since the target population of the scheme is the rural low-income farming community, the government attention and the contribution cannot be reduced. The relevant authorities should seek better ways to provide alternative funding for the FPSS.

Another important factor found was that the low level of awareness among the farming community leads to low willingness to pay and the lack of interest in the scheme. Therefore, suitable propaganda methods should be adopted to make them aware of the benefits of the scheme. To overcome the management problems, the administrative structure should be revised so as to have more field officers with efficient management. It is better to have direct Insurance Board officers at grass root level rather than having supportive agencies. Commission payments to supportive agencies, administrative costs and contribution for the group insurance fund which is for the payment of the non pension benefits should not be deducted from the contributions. Moreover, AAIB should act to avoid delays in issuing policy certificates, pension payments and charging the premium payment etc. More studies can be carried out for efficient premium and pension payment structures and should update the scheme accordingly. As pointed out by De Mel (2000), this is important as the phenomenon of aging has posed serious challenges to adequacy and supply of retirement income security arrangements all over the world.

\section{References}

Bateman, I.J. (2002). Economic Valuation with Stated Preference Techniques: A Manual, Edward Elgar, U.K.

De Mel, N. (2000). Ageing Population in Sri Lanka: Issues and Outlook on Retirement Income Arrangements. Sri Lanka Economic Journal, 1(1): 17-30. 
Eriyagama, V. and R.P. Rannan-Eliya (2003). Assessment of the Farmers' and Fishermen's Pension and Social Security Benefit Scheme in Sri Lanka. Institute of Policy Studies, Sri Lanka.

Shetty, S.L. (1971). An Inter-sectoral Analysis of Taxable Capacity and Tax Burden. Indian Journal of Agricultural Economics, 26:216-246. 